\title{
Effect of matrix rhythm therapy in diabetic foot ulcer healing:
}

\section{A case report}

\author{
Varun Naik' Chandra Bahadur Khatri2*, Ganesh BR
}

'Department of Cardiovascular and Pulmonary Physiotherapy, KAHER's Institute of Physiotherapy, Belagavi, Karnataka, India

${ }^{2}$ KAHER institute of Physiotherapy, Nehrunagar, Belagavi, Karnataka, India

Corresponding author: Chandra Bahadur Khatri (E-mail: cbkbharat@gmail.com)

\begin{abstract}
Introduction: Diabetic foot ulcer is one of the major complications following diabetes. In India, 15\% of diabetic patient develop DFU once in their lifetime. Neuropathy associated with diabetes is a major factor in development of foot ulcer in such patients. Infection, peripheral arterial diseases, altered functions of white blood cells, stem cells and regenerating tissues, and co-morbidities lead to delayed wound healing. Matrix rhythm therapy is a recent advancement in the field of Physiotherapy. It provides external oscillation that activates normal rhythm of cell that is between 8 and $12 \mathrm{~Hz}$ which improves cellular function within cell and extracellular matrix, enhancing tissue healing. A 70-year-old female presented with infected diabetic foot ulcer on her right foot in out-patient department of KLE hospital. She had nonhealing ulcer since one and half months and undergone conservative treatment of wound care along with strategies of diabetic foot care. Clinical findings: Subject complained of pain with score of 2 at rest and 6 while walking which was recorded on the basis of Visual Analogue Scale. Wound appeared ischemic and non-healing. On wound assessment, size of wound was $12 \mathrm{~mm}$ in diameter and $6 \mathrm{~mm}$ depth. It was identified as Type D grade I on the basis of classification of wound provided by University of Texas Health Science center.

Intervention: Matrix rhythm therapy was applied on posterior aspect of leg region extending around wound area once a week for 5 weeks with treatment duration of $1 \mathrm{~h}$.

Result: Pain of the subject after 5 weeks of intervention was 0 at rest and 2 while walking on the basis of VAS. Size of wound decreased with dimension of $6 \mathrm{~mm}$ in diameter and $2 \mathrm{~mm}$ depth and categorized as Type A grade 1.

Conclusion: Matrix rhythm therapy could be considered as adjunct in wound healing of diabetic foot ulcer.

Key words: Diabetic foot ulcer, matrix rhythm therapy
\end{abstract}

\section{Introduction}

Diabetes mellitus (DM) is a metabolic disorder characterized by chronic hyperglycemia which is due to alteration in insulin production and its action. ${ }^{1} \mathrm{DM}$ affects multiple systems in our body leading to complications such as retinopathy, nephropathy, neuropathy, cardiovascular diseases, and other complications such as infections and cognitive impairment. ${ }^{2}$ Diabetic foot ulcer (DFU) is one of the major complications following diabetes in an individual that leads to substantial morbidity. Prevalence of DFU in UK is around 7\% and USA is $8 \%$ and lifetime risk is $15 \%$. In India, around $15 \%$ of patients with diabetes are affected by DFU during their lifespan. Out of this proportion, $50 \%$ is infected that requires hospitalization and $20 \%$ need amputation in India. DFU alone contributes $80 \%$ of non-traumatic amputation and have huge burden in terms of expenses and morbidity. ${ }^{3,4}$

There are several factors which contribute in the development of diabetic ulcer; however, neuropathy and ischemia due to peripheral vascular diseases are the major contributing factors. In diabetic patient, production of nerve cell myoinositol that regulates normal neural conduction is hampered. This affects all the components of neural functions including motor, sensory and autonomic functions. Deformities such as claw-toe and high arched foot are the result of motor nerve involvement in diabetic patients that results in uneven distribution of force in foot, and thus formation of callus and skin breakdown. Dryness of skin and peripheral edema is a result of autonomic dysfunction in diabetic that leads to development of fissured skin. Decreased perception of pain and sensation leads to inability to detect any injury in subjects with diabetes due to which wound goes unnoticed for several duration until it gets worsened. Endothelial dysfunction associated with diabetes results in atherosclerosis which contributes in decreased blood supply. ${ }^{5-7}$

Wound healing is a complex process that follows a well-designed pattern of various biological and molecular events. Certain intrinsic factors and extrinsic factors such as neuropathy, vasculopathy, immunity, wound infection, wound cell abnormalities contributes in delayed wound healing in diabetic population. Early detection and intervention is needed in order to enhance healing process in DFU which can also predict the long-term progression. ${ }^{8,9}$ Identification of associated risk factors and its management can prevent DFU. ${ }^{10}$ Several guidelines have been published that provides information regarding management of diabetic foot ulcer which can be broadly divided into surgical and conservative management. Surgical management includes debridement and amputation. Conservative management includes prescription of protective footwear, pharmacological management of infection and restoration of perfusion, wound care through regular inspection and debridement, controlling of optimal glucose level, and educating patients regarding self care and management. ${ }^{11-13}$ Adjunctive therapies such as negative pressure wound therapy, hyperbaric oxygen therapy, and electrotherapy along with other physical agents such as ultrasound therapy, ultraviolet ray therapy, low laser therapy have been used to enhance healing of wound. ${ }^{14,15}$

Matrix rhythm therapy is a therapeutic method developed and improved by Dr. Ulrich Randall that is based on a fact 
that all cells of biological system follow a rhythmic pattern of vibrations when they are living. This conclusion was drawn from a research conducted at Erlangen University in Germany. Matrix rhythm therapy delivers the vibrations ranging from 8 to $12 \mathrm{~Hz}$ that mimics normal oscillation that brings changes in cellular level thereby enhancing the function at cellular level (within cell and extracellular matrix). ${ }^{16}$

\section{Patient information}

A 70-year-old female presented with open wound on the plantar aspect of her right foot which was evident since one-andhalf months. She complained pain at the site of wound which is aggravated on walking or weight bearing on same side. She gave the history of trauma due to uneven foot placement on a pebble. She noticed a wound on foot after a week of injury and applied local wound ointment for a month. Wound was increasing in size along with pain during weight bearing. She consulted physician and was referred to physiotherapy department for further management.

Subject gave the history of diabetes and hypertension since 20 years and 30 years, respectively, and under medication. She takes 16 units and 10 units of insulin in the morning and night for the management of diabetes and diuretics and ace inhibitors for hypertension management. She had undergone coronary artery bypass graft 16 years back.

\section{Clinical findings}

Pain assessment: Visual analogue scale was used to assess pain. It was $2 / 10$ at rest and $6 / 10$ while walking.

Wound examination: Size of wound was $12 \mathrm{~mm}$ diameter with $6 \mathrm{~mm}$ of depth which was located lateral aspect of posterior one-third on plantar surface of right foot. Wound appeared dry with calcified vascular tissues. Granulation tissues were minimal in appearance. Wound bed was filled with pus suggestive of infection.

Diagnostic assessment: Physical examination was carried out along with an X-ray. X-ray findings were normal to the age of the subject.

Wound was classified on the basis of diabetic wound classification system provided by The University of Texas Health Science Center. Wound was identified as Type D grade I.

Pain was assessed on the basis of visual analogue scale which was recorded as $20 \mathrm{~mm}$ on rest and $70 \mathrm{~mm}$ on weight-bearing activities.

\section{Therapeutic intervention}

Matrix rhythm therapy was performed on the affected limb. It was applied starting from posterior aspect of knee joint extending around the wound. Treatment was given for 5 sessions lasting up to $1 \mathrm{~h}$ in each session. Frequency of treatment was 1 session per week.

\section{Follow-up and outcomes}

Outcome measures were recorded in terms of size of the wound, grading of wound and VAS for pain. Subject has followed up till 1 month after cessation of treatment. Figure 1 shows appearance of wound before and after intervention of Matrix Rhythm Therapy.

First follow-up:

- VAS: 2 at rest and 6 on walking

- Shape of wound: It changed to rectangular shape from circular

- Size of wound: length=10 $\mathrm{mm}$, breadth: $6 \mathrm{~mm}$ and depth: $5 \mathrm{~mm}$

- Grading: Type C, Grade I

- Appearance: Ischemic, with partial vasularization of surrounding tissues

Second follow-up:

- VAS: 0 at rest and 5 on walking

- Shape of wound: rectangular

- Size: length $=8 \mathrm{~mm}$, breadth $=8 \mathrm{~mm}$, depth: $5 \mathrm{~mm}$

- Grading: Type C, grade I

Third follow-up:

- VAS: 0 at rest and 3 while walking

- Shape of wound: oval

- Size: greatest length $=8 \mathrm{~mm}$, greatest breadth=5 mm, depth $=4 \mathrm{~mm}$

- Grading: Type B, grade I

Fourth follow up:

- VAS: 0 at rest and 2 while walking

- Shape of wound: irregular

- Size: Greatest length: $6 \mathrm{~mm}$, greatest breadth=4 mm, depth $=2 \mathrm{~mm}$

- Grading: Type A, grade I

No any adverse effects or intolerance was observed or experienced by subject throughout the treatment sessions and follow-ups. At the end of session, wound changed from non-healing ulcer to healing ulcer with vascularization of surrounding tissues.

\section{Discussion}

Our study aimed to determine the effects of matrix rhythm therapy on diabetic foot ulcer. Application of matrix rhythm therapy for five sessions, one session a week showed accelerated wound-healing process in non-healing diabetic foot ulcer along with decreased pain intensity. This study is novel of its kind which is applied for wound healing, and till now no published literature is available.

DFU is of the major complications that lead in disability and decreased quality of life in diabetic population. Multiple approaches have been applied for the prevention and management of DFU but effective approach that enhances healing of ulcer is not established. Several physical modalities such as low level laser, ultraviolet radiation, electrical stimulation have been used in management of wound but most of the studies lack quality of evidence and physiological basis for wound healing. ${ }^{15}$ Most of the studies related to the physiotherapy approaches in wound healing have used multiple therapeutic methods which lead overlapping of physiological effects and results cannot be specified to a particular method. ${ }^{17,}{ }^{18}$ In our study, we have used only matrix rhythm therapy and its effect on wound can be specified. 


\section{Pre}

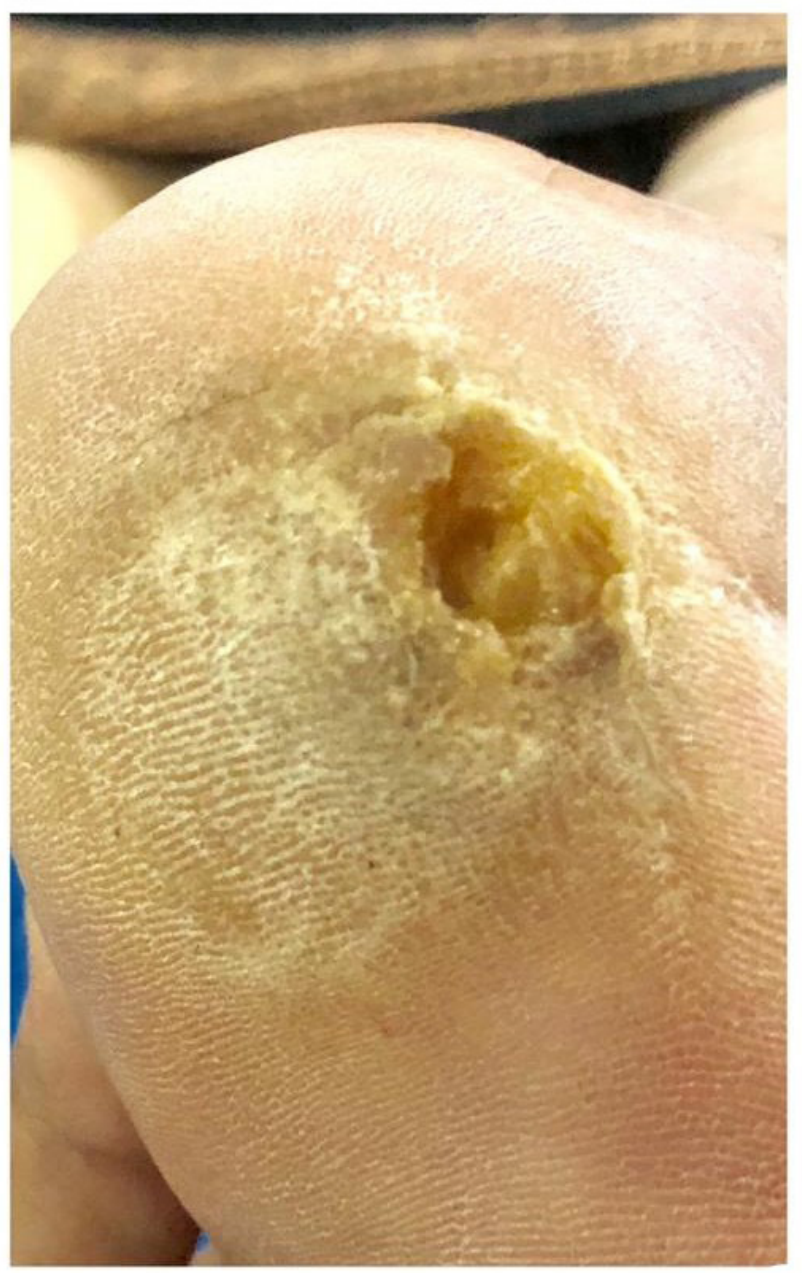

\section{Post}

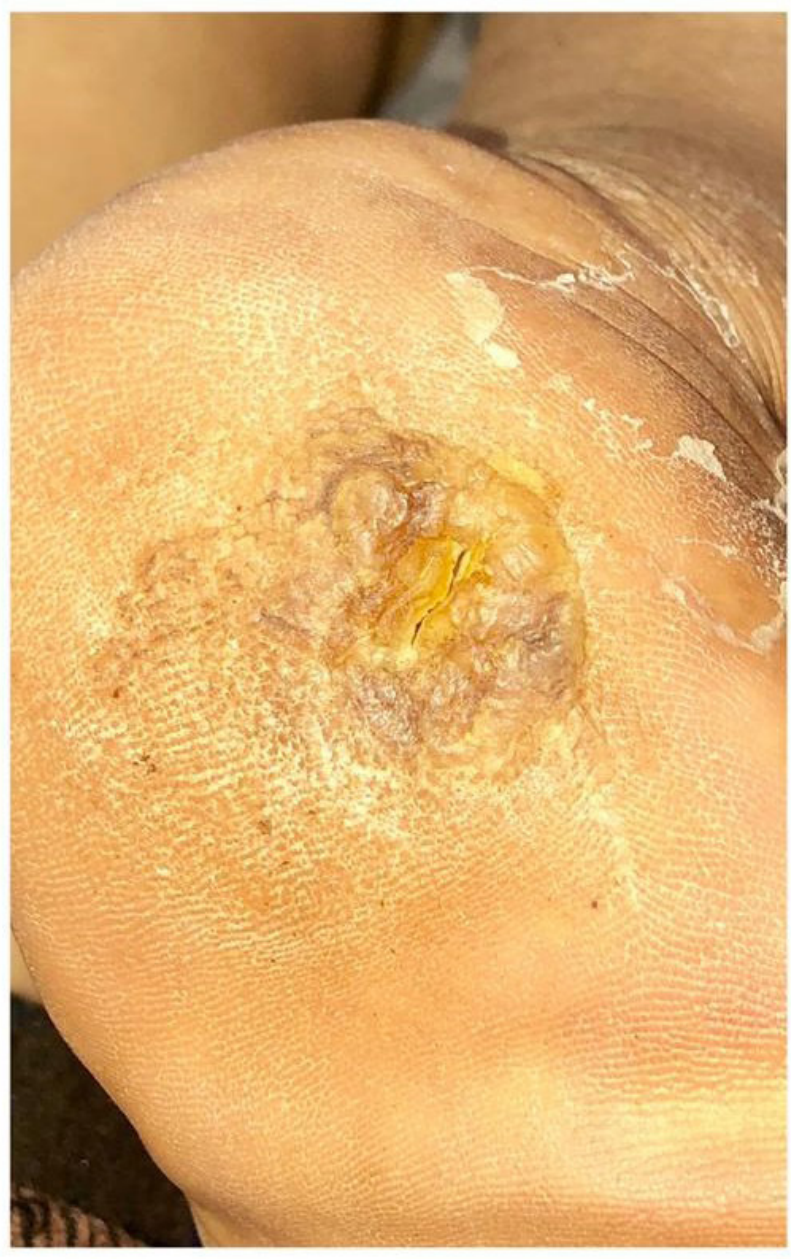

\section{Fig. 1}

Use of vibrations as interventions for therapeutic benefit has history since 19th century. Vibrations has been used for management of neurological conditions, increasing power and flexibility in athletes, maintenance of bone density in astronauts, and recently it has been used to enhance wound-healing process. A study was done in regarding the effect of vibration in healing process in diabetic mice. It has been found that vibrations produces stimulus that helps in release of growth factors, stem cell proliferation, and cell differentiation when applied to bone. In wound, it increases angiogenesis, formation of granulation tissues, and promotes the accumulation of macrophages, fastens the wound closure, and re-epithelialization. They also found that there is decrease in number of neutrophils cells in wound that decreases the inflammatory conditions within wound. Similarly, there was decrease in blood glucose levels and increase in microcirculation after application of vibrations. ${ }^{20,21}$ In these, studies the frequency of vibrations applied was $35-45 \mathrm{~Hz}$ compared to physiological oscillations/vibrations in our study. Though one of study on effects of vibrations in blood flow in healthy inactive subjects showed that vibration is responsible for increase in blood supply, there are very limited studies related to role of vibrations in wound healing in diabetic subjects. ${ }^{22}$

In our study, wound healing in DFU is accelerated that can be possibly due to cellular effect of vibrations produced by the application of matrix rhythm therapy. Matrix rhythm therapy produces oscillations of $8-12 \mathrm{~Hz}$ in cells that mimics the normal rhythmic oscillations when cells are alive. In diseased condition, normal rhythmic oscillations are affected thereby impairing functions within cells and its surrounding environment, i.e., extracellular matrix. Following application of this therapeutic approach normal oscillations can be restored leading to normal function of cell and its environment. ${ }^{19}$ Similarly, application of matrix rhythm therapy leads to increased circulation which was observed in a study done in athletes. In their study, they compared the effects on circulation by using conventional massage with matrix rhythm therapy. They concluded that, matrix rhythm therapy leads to 
increase in circulation through compression effect and soft tissue mobilization along with contraction of muscles produced by stimulation of tonic vibration reflex. ${ }^{23}$

There are certain limitations of the study despite being first of its kind to intervene matrix rhythm therapy. More emphasis would have been given in detailed objective examination of diabetic foot ulcer and intervention frequency was less which could have been increased. In future, more number of patients can be involved as to develop a case series and can be compared with other physical modalities.

In conclusion, matrix rhythm therapy may be used as an adjunctive therapy for wound healing in diabetic foot ulcer. It could be beneficial in not only enhancing healing of wound but also overall improvement on functions of cell and its environment thereby creating optimal atmosphere.

Informed consent: Was duly obtained from subject regarding recoding and publication of data

\section{Source of Funding: Nil}

\section{Conflict of Interest: Nil}

\section{References}

1.World Health Organization. Definition, diagnosis and classification of diabetes mellitus and its complications: Report of a WHO consultation. Part 1 Diagnosis and classification of diabetes mellitus. Geneva: World health organization; 1999.

2. Nathan DM. Long-term complications of diabetes mellitus. New Engl J Med. 1993 Jun 10;328(23):1676-85.

3. Jeffcoate WJ, Harding KG. Diabetic foot ulcers. Lancet. 2003 May 3;361(9368):1545-51.

4. Ghosh P, Valia R. Burden of diabetic foot ulcers in India: Evidence landscape from published literature. Value Health. 2017 Oct 1;20(9):A485.

5. Clayton W, Elasy TA. A review of the pathophysiology, classification, and treatment of foot ulcers in diabetic patients. Clin Diab. 2009 Apr 1;27(2):52-8

6. Bowering CK. Diabetic foot ulcers. Pathophysiology, assessment, and therapy. Can Family Phys. 2001 May 1;47(5):1007-16.

7. Noor S, Zubair M, Ahmad J. Diabetic foot ulcer - a review on pathophysiology, classification and microbial etiology. Diab Metab Syndr Clin Res Rev. 2015 Jul 1;9(3):192-9.
8. Falanga V. Wound healing and its impairment in the diabetic foot. Lancet. 2005 Nov 12:366(9498):1736-43.

9. Apelqvist J, Larsson J, Agardh CD. Long-term prognosis for diabetic patients with foot ulcers. J Intern Med. 1993 Jun;233(6):485-91.

10. Singh $N$, Armstrong DG, Lipsky BA. Preventing foot ulcers in patients with diabetes. JAMA. 2005 Jan 12;293(2):217-28.

11. Piaggesi A, Schipani E, Campi F, Romanelli M, Baccetti F, Arvia C, Navalesi R. Conservative surgical approach versus non-surgical management for diabetic neuropathic foot ulcers: a randomized trial. Diab Med. 1998 May;15(5):412-7.

12. Lipsky BA, Berendt AR, Deery HG, Embil JM, Joseph WS, Karchmer AW, LeFrock JL, Lew DP, Mader JT, Norden C, Tan JS. Diagnosis and treatment of diabetic foot infections. Clin Infect Dis. 2004 Oct 1:885-910.

13. Bakker K, Apelqvist J, Schaper NC, International Working Group on the Diabetic Foot Editorial Board. Practical guidelines on the management and prevention of the diabetic foot 2011. Diab Metab Res Rev. 2012 Feb;28:225-31.

14. Stansby G, Avital L, Jones K, Marsden G. Prevention and management of pressure ulcers in primary and secondary care: Summary of NICE guidance. BMJ. 2014 Apr 23;348:g2592.

15. Zhou K, Krug K, Brogan MS. Physical therapy in wound care: A costeffectiveness analysis. Medicine. 2015 Dec;94(49).

16. The Matrix Concept in Practice - Dr. Randoll Institut - Gemeinnützige Gesellschaft für Matrix-Forschung und -Lehre mbH [Internet]. [20.04.2019]. Available from: https://www.dr-randoll-institut.de/en/matrix-konzept-inder-praxis.

17. Ketan Bhatikar. Effect of matrix rhythm therapy on chronic vein dysfunction deep foot ulcer: A case report. J Yoga Physio. 2018;6(5):555696. DOl: 10.19080/JYP.2018.06.555696.

18. Sari Z, Polat MG, Özgül B, Aydoğdu O, Camcıoğlu B, Acar AH, Yurdalan SU. The application of matrix rhythm therapy as a new clinical modality in burn physiotherapy programmes. Burns. 2014 Aug 1;40(5):909-14.

19. Randoll UG, Hennig FF. Coherent rhythms (timing frequencies) in biological systems as a basis for the matrix-rhythm. Therapy. 2003.

20. Weinheimer-Haus EM, Judex S, Ennis WJ, Koh TJ. Low-intensity vibration improves angiogenesis and wound healing in diabetic mice. PLoS One. 2014 Mar 11;9(3):e91355.

21. Yu CO, Leung KS, Jiang JL, Wang TB, Chow SK, Cheung WH. Low-magnitude high-frequency vibration accelerated the foot wound healing of n5streptozotocin-induced diabetic rats by enhancing glucose transporter 4 and blood microcirculation. Sci Rep. 2017 Sep 14;7(1):11631.

22. Gailiūnienè L, Krutulytė G, Šiaučiūnaitè V, Savickas R, Venslauskas M. The effect of low frequency 2-10 Hz vibrations on blood circulation in lower extremities. J Vibroeng. 2017 Sep 30;19(6):4694-701.

23. Taspinar F, Aslan UB, Sabir N, Cavlak U. Implementation of matrix rhythm therapy and conventional massage in young females and comparison of their acute effects on circulation. J Altern Complem Med. 2013 Oct 1;19(10):826-32. 